\title{
ALUMUNIUM BAHAN ANTENA UNTUK OPTIMASI TRANSMISI GELOMBANG RADIO
}

\author{
Roni Kartika Pramuyanti \\ Program Studi Teknik Elektro, Fakultas Teknik \\ Universitas Semarang \\ Email: elektro@umk.ac.id
}

\begin{abstract}
ABSTRAK
Antena merupakan instrumen pada elektronika telekomunikasi yang sangat berguna pada pentransmisian gelombang suara baik gelombang audio maupun radio. Banyak bahan pembuat antena yang bisa digunakan, antara lain besi, kuningan, tembaga dan alumunium. Semua bahan yang disebutkan adalah bahan-bahan konduktor yang mudah dalam menghantar arus listrik. Dari penelitian ini diharapkan akan diperoleh bahan dasar antena yang dapat meng optimasikan gelombang radio. Metode yang digunakan untuk mengetahui hal ini adalah dengan membuat antena dari dari bahan-bahan yang biasa dibuat sebagai bahan dasar antena. Semua bahan untuk membuat antena yang disebutkan sebelumnya telah dicoba dan diteliti, ternyata hanya satu bahan dasar saja yang bisa digunakan sebagai bahan pembuat antena yang mudah serta ringan yaitu Alumunium. Beberapa parameter yang menyertai pada pembuatan antena yang semuanya ada pada Alumunium, dapat diatasi, diketahui dan bahkan diketemukan. Antara lain bentuk dan diameter permukaan, impedansi, daya pancar, daya terima serta SWR.
\end{abstract}

Kata kunci: antenna, konduktor, optimal, alumunium, daya pancar, daya terima, SWR.

\section{ABSTRACT}

The Antena is one of electronic's communication instrument which very usable to transmitted the radio and audio sound wave. There are many basic materials of antenna which can usable, the among others iron, brass, copper, aluminum. All of the badic materials is the materials which can be conductor. From this research, All of the materials to make an antenna has been studied previouslycan make the optimation of radio's wave. The metode to know that is make the antenna with use all of the basic materials. But only one material can be used as be base material antenna. That's alumunium, that's lightweight, malleable. Some parameters which follow in use of antenna there is on alumunium caa be solve, known and found. Among others things, the shape and surface parameters, impedance, transmit power, receive power, and SWR antenna.

Keywords: antenna, conductor, optimal, alumunium, transmited power, receive power, SWR.

\section{PENDAHULUAN}

Antena adalah perangkat yang digunakan untuk transmisi gelombang, mengirim dan menerima sinyal. Antena dibuat dari bahan konduktor dengan berbagai bentuk sesuai dengan fungsi penerapannya. Salah satu jenis Antena yang kita bahas disini adalah Antena Yagi. Transmisi utama energi dari sntena terjadi dalam derah luar konduktor, karena setiap medan yang berubah terhadap waktu akan mengalami atenuasi yang sangat cepat di dalam konduktor yang baik.

Antena yang baik adalah antenna yang bias menyeimbangkan serta memaksimalkan daya pancar dan daya terima antenna. Beberapa hal yang perlu diketahui pada daya hantar maupun pancar antena adalah adanya tahanan yang akan mempengaruhi besarnya frekuensi pancaran maupun penerimaan dari gelombang radio. Untuk itu telah dicoba untuk menganalisa ada dan tidaknya tahanan pada konduktor dari antena yang digunakan.

Kecenderungan gelombang merambat pada permukaan penghantar sehingga perlu dipilih bahan dan bentuk konduktor yang sesuai dan dapat digunakan untuk pentransmisian gelombang radio dapat optimal. Penelitian dan pembahasan dari masalah ini akan dibatasi pada 1. jenis bahan konduktor yang paling sesuai, 2. Batas frekuensi radio yang dapat dipancarkan serta diterima dari antena yang dibuat dengan bahan konduktor tersebut.

\section{METODOLOGI PENELITIAN}

Penelitian ini dilakukan dengan menggunakan metode :1. Studi literatur, 2. Pembuatan antena dengan bahan beberapa konduktor, 3 . Survei lokasi untuk penerapan dan aplikasi antena yang dibuat dari bahan sebuah konduktor saja. 


\subsection{Studi Literatur}

Sambil melakukan penelitian, penulis membaca serta mempelajari beberapa buku atau literatur yang menunjang penelitian yang tengah dilakukan, serta membandingkannya dengan penelitian yang sudah ada sebelumnya.

\subsection{Pembuatan Antena Dengan Bahan Beberapa Konduktor}

Untuk menunjang keberhasilan dan kelancaran penelitian ini, peneliti melakukan pembuatan antenna dengan menggunakan beberapa konduktor yang telah disebutkan sebelumnya. Perancangan bentuk/ model antena yang akan diteliti menggunakan bahan konduktor yang ada :

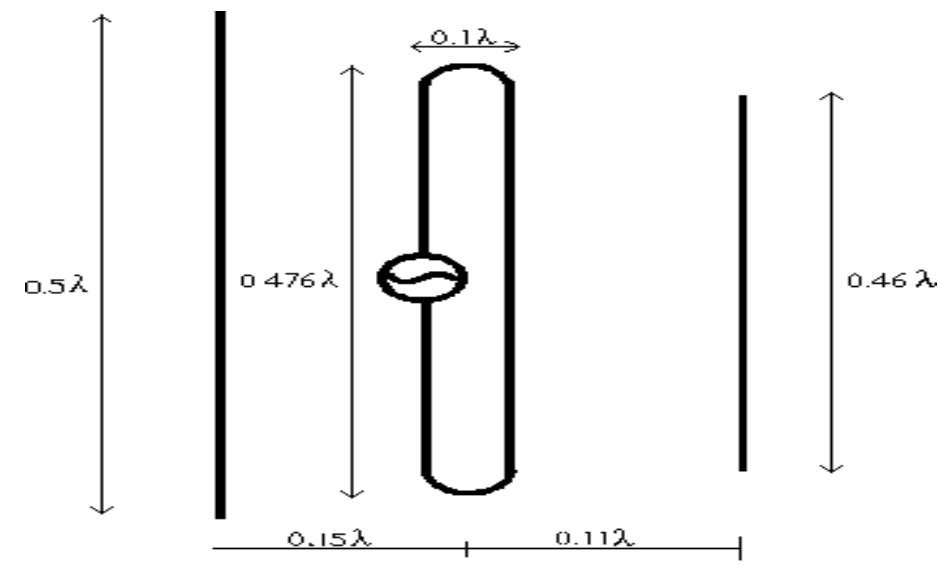

(a)

(b)

(c)

Gambar 1. Tiga elemen pokok antena : a. direktor, b. Driven/radiator (Dipole yang dilipat simetris) penerima utama, c. reflektor

Keuntungan/ perolehan/ gain diberikan oleh :

$\mathrm{G}=10 \log \mathrm{n}$

Keterangan'n' adalah jumlah elemen yang perlu dipertimbangkan.

Selama tiga elemen Yagi antena, jarak antara reflektor dan driven utama tersebut $0.15 \lambda$, antara direktor dan driven utama 0.11 $\lambda$. Ini jarak pemisahan antara elemen mereka yang memberikan keuntungan yang optimal, karena jika tidak menggunakan jarak tersebut dapat mengganggu satu sama lain, menurunkan gain .

Gambar di atas kita dapat melihat arus dan tegangan distribusi lebih dari dipole setengah gelombang. Setiap tiang antena terlihat seperti bagian terbuka dari seperempat panjang gelombang dari saluran transmisi . Oleh karena itu di ujung ada tegangan maksimum dan minimum, arus dan tegangan minimum dan maksimum ada pula di pusat. Oleh karena itu, dengan asumsi bahwa titik di tengah antena , impedansi masukan adalah $\mathrm{E}_{\text {minim }} / \mathrm{I}_{\text {maxim }}$ dan nilai minimum . Impedansi pada antena berakhir $\mathrm{E}_{\text {maxim }} /$ $\mathrm{I}_{\text {minim }}$ dan nilai maksimum . 


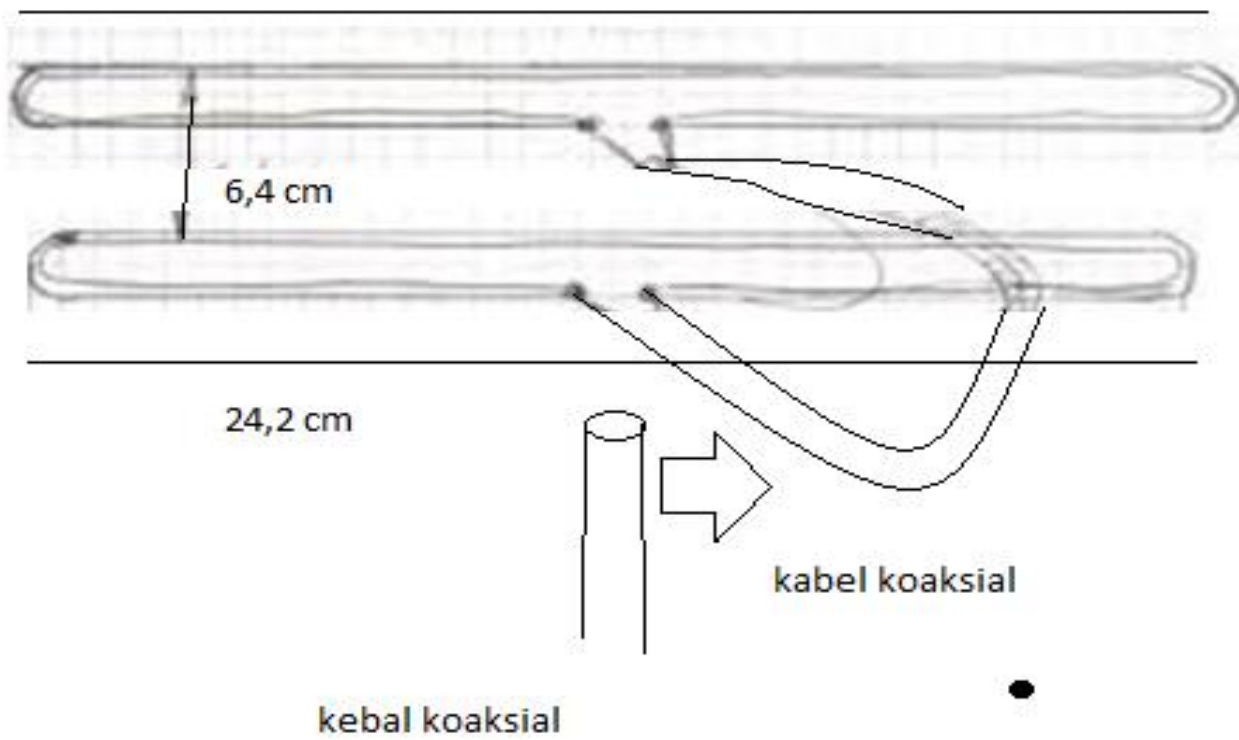

Gambar 2. Perancangan Antena Yagi yg Dibuat (cara membuat antenna yagi)

Yagi Antena : Antena terdiri dari beberapa paralel dan planar array, direksi, aset (x) dan reflektor, banyak digunakan dalam penerimaan. Prinsip elemen mengarahkan medan listrik, driven element yang memancarkan aset (x) dan reflektor mencerminkan hal ini. ( Gambar 9 di bawah). Unactivated disebut elemen parasit , antena dapat memiliki beberapa elemen aktif Yagi dan berbagai parasit .

Perolehan (Gain) antena didapatkan dari :

$\mathrm{G}=10 \log \mathrm{n}$

(dimana $\mathrm{n}$ adalah jumlah elemen yang perlu dipertimbangkan).

Selama tiga elemen Yagi antena jarak antara direktor dan driven $\mathrm{x}$ tersebut $0.15 \mathrm{~L}$, antara driven $\mathrm{x}$ dan reflektor $0.11 \mathrm{~L}$. Ini jarak pemisahan antara elemen adalah mereka yang memberikan keuntungan yang optimal, karena jika bidang barang destruktif mengganggu satu sama lain, menurunkan gain. Seperti dapat dilihat, ini desain antena Yagi ditemukan menjadi sempit, sebagai elemen dipole dipotong pada satu frekuensi biasanya dipilih $2(50 \mathrm{MHz}$ sampai $86 \mathrm{MHz}$ serta antara $110 \mathrm{MHz}-115 \mathrm{MHz})$. Hal ini terbukti menjadi suatu kerugian karena tidak mungkin untuk menutupi beberapa TV dengan satu gain yang dipilih. Untuk alasan ini yang disebut broadband antena Yagi yang digunakan, yang dapat mencakup beberapa saluran sekaligus sementara mengorbankan keuntungan.

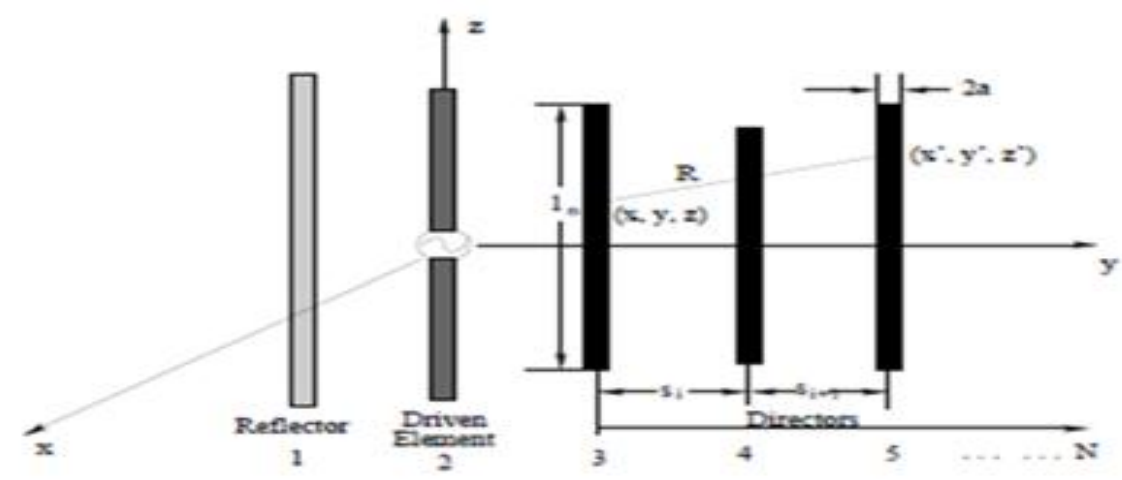

Gambar 3. Bagian Antena Yagi Driven Element memancarkan Aset (x) 


\subsection{Survei Lokasi Untuk Mencoba Antena Yang Dibuat}

Setelah menyelesaian antenna terutama yang berbahan dasar Alumunium, dicari tempat yang cukup lapang untuk mencoba atau mengaplikasikan antenna tersebut. Dari aplikasi ini diharapkan akan fiperoleh serta dihitung daya pancar serta daya terima yang dimiliki antenna.

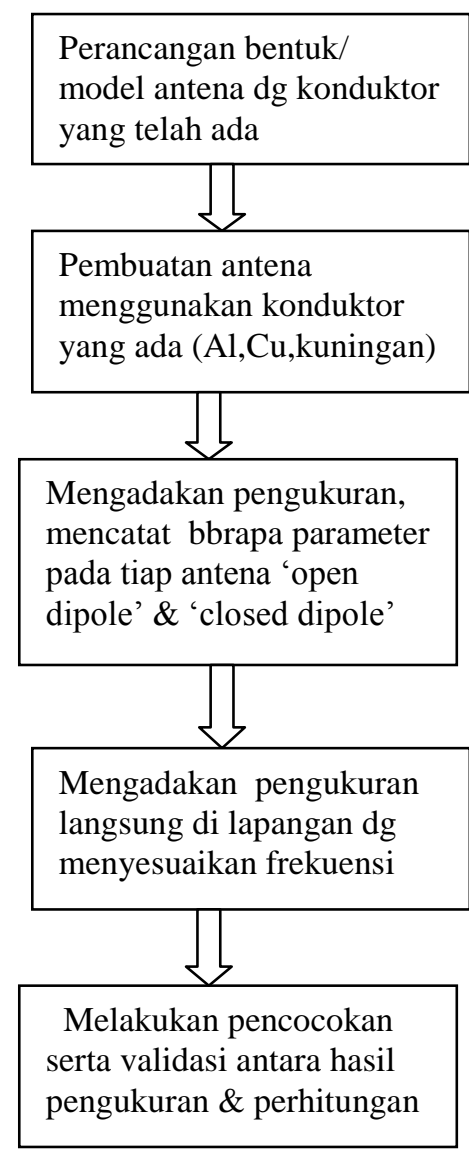

\section{Gambar 4. Blok Langkah-langkah Yang dilakukan pd penelitian}

\section{HASIL DAN PEMBAHANSAN}

Penelitian imi memberikan 2 macam hasil yaitu hasil berupa data tertulis untuk dianalisa secara teori \& rumus, serta hasil penelitian yang berupa penerapan langsung di lapangan.

\subsection{Hasil Penelitian Laboratorium}

Data perubahan daya dan berdasarkan perubahan frekuensi dari antena bahan antena: Alumunium tabung 
Tabel 1. Data perubahan daya berdasar perubahan frekuensi antena Daya 1 antena penerima, daya 2 antena pemancar [4]

\begin{tabular}{cccc}
\hline frekw $(\mathbf{M H z})$ & daya 2 & frekw $(\mathbf{M H z})$ & Daya $\mathbf{~}$ \\
\hline 10 & 0,05 & 10 & 0,01 \\
20 & 0,055 & 20 & 0,015 \\
30 & 0,06 & 30 & 0,02 \\
40 & 0,065 & 40 & 0,02 \\
50 & 0,065 & 50 & 0,03 \\
60 & 0,07 & 60 & 0,03 \\
70 & 0,075 & 70 & 0,035 \\
80 & 0,08 & 80 & 0,035 \\
90 & 0,09 & 90 & 0,04 \\
100 & 0,5 & 100 & 0,6 \\
$110 \leftarrow$ & 0,8 & $110 \leftarrow$ & 0,8 \\
120 & 0,3 & 120 & 0,4 \\
130 & 0,25 & 130 & 0,35 \\
140 & 0,3 & 140 & 0,4 \\
150 & 0,25 & 150 & 0,3 \\
160 & 0,2 & 160 & 0,4 \\
170 & 0,6 & 170 & 0,45 \\
180 & 0,4 & 180 & 0,4 \\
190 & 0,3 & 190 & 0,4 \\
200 & 0,25 & 200 & 0,3 \\
\hline
\end{tabular}

* Alumunium tabung

Tabel 2. nilai R, f dan SWR

\begin{tabular}{l|l|l|l}
\hline a. $R=56 \Omega ;$ & $X=226 ;$ & $f=90,07 \mathrm{MHz} ;$ & SWR $=14,1$ \\
\hline b. $R=57 \Omega ;$ & $X=194 ;$ & $f=102,06 \mathrm{MHz} ;$ & SWR $=10,4$ \\
\hline c. $R=46 \Omega ;$ & $X=18 ;$ & $f=114,10 \mathrm{MHz} ;$ & SWR $=1,5$ \\
\hline d. $R=81 \Omega ;$ & $X=0 ;$ & $f=116,10 \mathrm{MHz} ;$ & SWR $=1,5$ \\
\hline
\end{tabular}

* Alumunium Pejal

Tabel 3. nilai R, f dan SWR

\begin{tabular}{l|l|l|l}
\hline a. $R=42 \Omega ;$ & $X=262 ;$ & $f=93,09 \mathrm{MHz} ;$ & SWR $=22$ \\
\hline b. $R=52 \Omega ;$ & $X=39 ;$ & $f=94,07 \mathrm{MHz} ;$ & SWR $=23,3$ \\
\hline c. $R=60 \Omega ;$ & $X=329 ;$ & $f=95,09 \mathrm{MHz} ;$ & SWR $=26,2$ \\
\hline d. $R=7 \Omega ;$ & $X=9 ;$ & $f=64,05 \mathrm{MHz} ;$ & SWR $=6,5$ \\
\hline
\end{tabular}

Pengukuran perubahan daya berdasarkan perubahan frekuensi dengan harga dari

SWR Analyser didapat harga seperti pada tabel diatas. Adapun dari data diatas akan dapat dihitung :

a. panjang gelombang dari frekuensi dengan daya terbesar $\left(\lambda=\frac{\varepsilon}{f}\right.$, dimana $\mathrm{c}:$ cepat rambat cahaya di udara, $\mathrm{f}:$ frekuensi data.

b. kuat sinyal dari daya terbesar $=10 \log \mathrm{n} ;\left(\mathrm{n}=\frac{P_{1}}{P_{2}}\right)$

Dari alat SWR Analyser pula dapat dibaca atau diketahui harga tahanan murni/ Resistensi (R), Reaktansi (X) sehingg akan dapat dihitung besar impedansi serta SWR antena yang digunakan.

\subsection{Hasil Penelitian Lapangan}

Setelah pembuatan antena yagi selesai, telah dilakukan beberapa pengamatan dengan menggunakan beberapa peralatan : antena yang telah selasai dibuat (seperlunya), SWR analyser serta beberapa potong $\mathrm{kabel} /$ probe yg menghubungkan antara antena dan SWR analyzer. 
Dari pengukuran diatas, selanjutnya dilakukan pula aplikasi langsung atau penelitian lapangan. Adapun peralatan yang diperlukan adalah : antena, kabel konektor serta measurement reciever. Dari penelitian lapangan ini akan dicari atau dianalisa penerimaan suara yang paling jelas berdasarkan frekuensi serta tahanan atau impedansi yang telah dicari atau diteliti sebelumnya berdasarkan hasil pengukuran.

Contoh dari data yang dicoba dan dilakukan : Alat yang digunakan untuk penerimaan : measurement Reciever: pada frekuensi yg diterima 96,8 MHz. kuat sinyal yg diterima $=16,5 \mathrm{~dB} \mu \mathrm{V}$; $17,8 \mathrm{~dB} \mu \mathrm{V} \&$ kuat sinyal persatuan luas $19 \mathrm{dBm} \mu \mathrm{V} / \mathrm{m}^{2}$. Kuat sinyalygditerima $=\mathrm{Gain} /$ perolehan antena $=10 \log \mathrm{n}$. Impedansi antena didapat dari gabungan antara resistansi/ yahanan murni (R) dan reaktansi induktif yang ada $(X), Z=Z_{L}=\sqrt{R^{2}+X^{2}}$, perhitungan $S W R=\frac{z_{L}}{z_{0}} ;$ jika $z_{L}>>z_{o}$ atau $S W R=\frac{z_{0}}{z_{L}} ;$ jika $z_{0}$ $>\mathrm{Z}_{\mathrm{L}}$

\subsection{PEMBAHASAN}

Perhitungan berdasarkan data yang ada :

* Panjang gelombang antena $(\lambda)$, didapat dari data dengan frekuensi terbaik yang memancarkan atau menerima daya terbesar:

$$
\begin{aligned}
& \mathrm{f}=110 \mathrm{MHz}, \text { daya } 0,8 \mathrm{~W} \\
& \lambda=\frac{\varepsilon}{f}=\frac{a \cdot 10^{\mathrm{g}}}{110 \cdot 10^{6}}=0,027 \cdot 10^{2}=2,7 \mathrm{~m}
\end{aligned}
$$

* Impedansi Antena $Z=\sqrt{R^{2}+X^{2}}$

Harga R (Resistansi) dan X (Reaktansi) didapat dari data hasil pengamatan, yaitu :

a. $\mathrm{R}=56 \Omega ; \mathrm{X}=226 \Omega$

$$
Z=\sqrt{56^{2}+226^{2}}=232,83 \Omega
$$

b. $\mathrm{R}=57 \Omega ; \mathrm{X}=194 \Omega$

$\mathrm{Z}=\sqrt{57^{2}+194^{2}}=202,20 \Omega$

c. $\mathrm{R}=46 \Omega ; \mathrm{X}=18 \Omega$

$$
Z=\sqrt{46^{2}+18^{2}}=49,40
$$

d. $\mathrm{R}=81 \Omega ; \mathrm{X}=0 \Omega$

$$
\mathrm{Z}=\sqrt{81^{2}+0^{2}}=81 \Omega
$$

* Standing Wave Ratio (SWR) dari Impedansi $\mathrm{Z} / \mathrm{Z}_{\mathrm{L}}$ yang telah dihitung. Nilai SWR merupakan perbandingan dari $\mathrm{Z}\left(\mathrm{Z}_{\mathrm{L}}\right)$ dan $\mathrm{Z}_{0}$ yang berharga $50 \Omega$.

$\mathrm{SWR}=\frac{z_{L}}{z_{0}}=\frac{z_{0}}{z_{L}}$ harga SWR berdasarkan data dan perhitungan :

a. $\quad Z_{\mathrm{L}}=232,83 \Omega ; \mathrm{SWR}=\frac{\mathrm{z}_{\mathrm{L}}}{z_{0}}=\frac{232,9 \mathrm{al}}{50}=4,66$

b. $\quad Z_{L}=202,20 \Omega ; S W R=\frac{z_{L}}{z_{0}}=\frac{202,20}{50}=4,04$

c. $Z_{\mathrm{L}}=49,40 \Omega ; \mathrm{SWR}=\frac{\mathrm{z}_{0}}{z_{\mathrm{L}}}=\frac{50}{49,40}=1,01$

d. $\mathrm{Z}_{\mathrm{L}}=81 \Omega \quad ; \mathrm{SWR}=\frac{\mathrm{Z}_{\mathrm{L}}}{\mathrm{z}_{0}}=\frac{\mathrm{g1}}{50} \quad=1,62$

Penelitian lapangan menggunakan antena dengan bahan Alumunium tabung. Dari pengujian antena ini dicari gelombang yang diterima paling jelas menggunakan antena yang dibuat ( Gambar 10 ). Alat yang digunakan adalah antena yang dibuat, kabel konektor yang akan menghubungkan antena ke Measurement Reciever (penerima). Dari Measurement Reciever dapat dilihat :

frekuensi yang diterima : $96,8 \mathrm{MHz}$

Kuat sinyal yang diterima : $16,5 \mathrm{~dB}$

$$
17,8 \mathrm{~dB}
$$

Kuat sinyal yg diterima/ $\quad: 19 \mathrm{~dB} / \mathrm{m}^{2}$

Satuan luas

Dari hasil perhitungan, terlihat bahwa impedansi antena mempunyai nilai yang sebanding dengan SWRnya. Impedansi adalah suatu tahanan, sehingga harga impedansi semakin kecil akan membuat daya hantar dari antena menjadi besar. Secara teori, antena yang paling baik adalah antena yang mempunyai

SWR rendah

Impedansi antenna mendekati $50 \mathrm{Ohm}$

Sinyal yang diterima paling kuat 


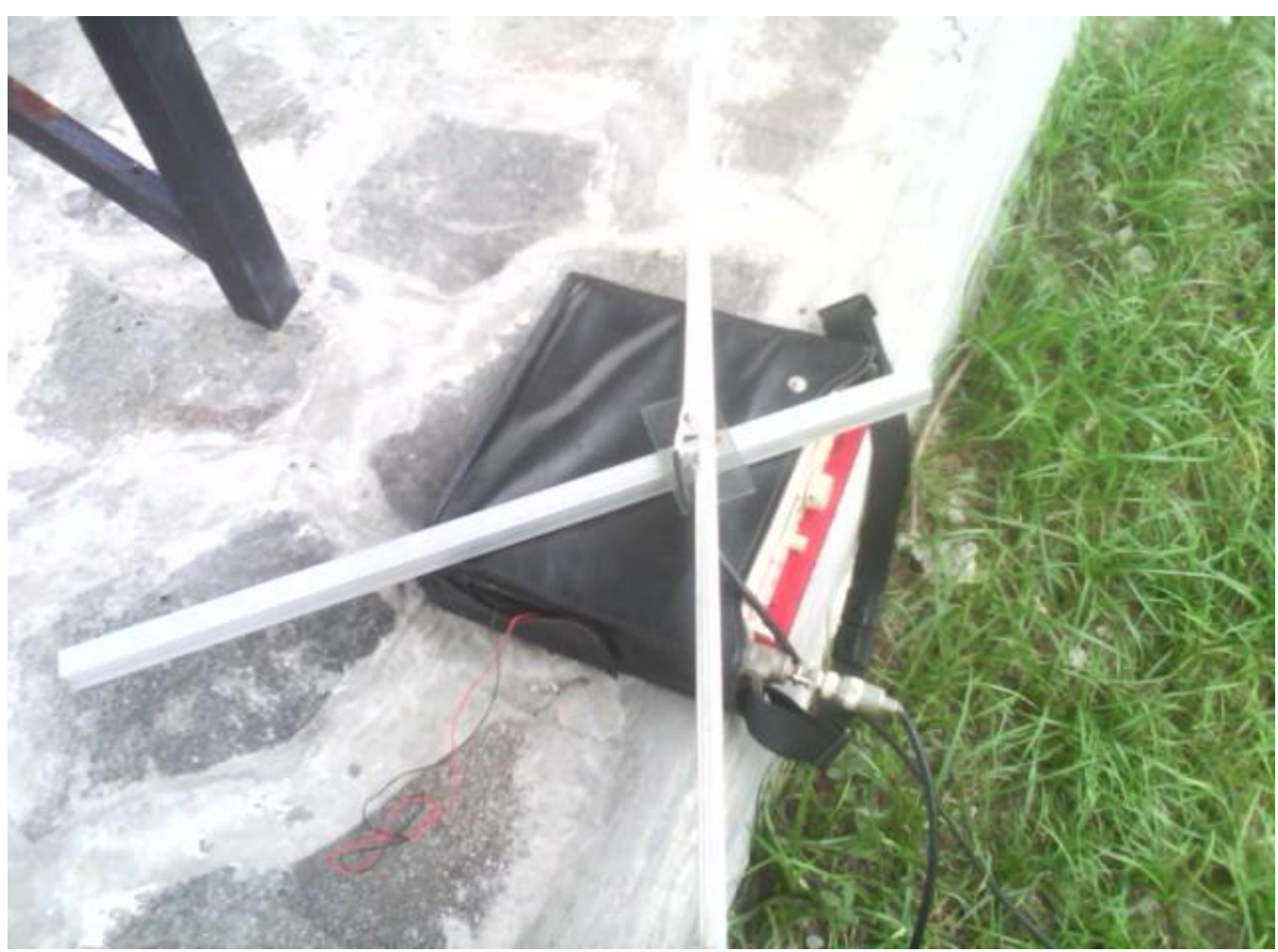

Gambar 3. Hasil pembuatan alat serta pengambilan data di lapangan

\section{KESIMPULAN}

Dari hasil pembahasan dan analisa, dapat diperoleh kesimpulan :

a. Hasil pengamatan di lapangan mempunyai harga yang sangat jauh berbeda dengan perhitungan atau pengamatan yang telah dilakukan sbelumnya, hal ini kemungkinan adanya faktor Error Pointing yang terjadi saat pengambilan data serta pengamatan lapangan.

b. Harga Standing Wave Ratio (SWR) semakin kecil adalah semakin baik. Dari penelitian diatas terlihat bahwa SWR mempunyai harga yang kecil (dibawah 20) adalah pada antena dengan bahan tabung, alumunium tabung, tembaga tabung dan kuningan tabung..

c. Dari hasil pengamatan dan pengukuran menggunakan SWR Analyzer, kecilnya harga SWR bersamaan pula dengan kecilnya harga reaktansi walaupun pada frekuensi sekitar 90,07 $\mathrm{MHz}$ dan $102,06 \mathrm{MHz}$ harga reaktansinya msih diatas $150 \Omega$, SWR mempunyai harga 14,1 dan 10,4. Pada Alumuniun harga SWR juga rendah yaitu 6,5 pada frekuensi 64, $05 \mathrm{MHz}$, reaktansi $11 \Omega$ serta resistansi $6 \Omega$.

d. Aplikasi atau penggunaan antena yang dibuat di lapangan, memberikan hasil kuat sinyal yang diterima (Gain) yang sangat jauh berbeda dari perhitungan pada frekuensi yang sama. Hal ini kemungkinan disebabkan adanya pergeseran nilai atau error pointing yang terjadi antara antena serta kondisi udara.

e. Bahan Alumunium tabung dan tembaga tabung sebagai konduktor saat digunakan sebagai bahan antena mempunyai nilai SWR yang kecil, untuk alumunium tabung juga mudah dalam pembentukannya.

\section{ACUAN REFERENSI}

Perbandingan bahan konduktor utk pentransmisian gelombang radio, Roni Kartika Pramuyanti.

\section{DAFTAR PUSTAKA}

[1] J. Kraus \& Rashefka (2001). Antenna (3 rd edition). Washington DC; Mc. Graw Hill.

[2] John Willey \& Son, 1997. Bidang Gelombang dalam Elektronika Komunikasi, 1997. New York ; John Willey \& Son Inc.

[3] Noname http://id.Wikipedia.org/wiki/Antenna_Yagi, tanggal 31 Desember 2013. 
[4] Roni Kartika, Ari Endang, M Sipan, 2014, Perbandingan Bahan Konduktor Untuk Pentransmisian Gelombang Radio, LPPM USM 